Article

\title{
Optofluidic Formaldehyde Sensing: Towards On-Chip Integration
}

\author{
Daniel Mariuta ${ }^{1,2}$, Arumugam Govindaraji ${ }^{1}$, Stéphane Colin ${ }^{2}\left(\mathbb{D}\right.$, Christine Barrot ${ }^{2} \oplus$, \\ Stéphane Le Calvé ${ }^{3,4}$, Jan G. Korvink ${ }^{1}\left(\mathbb{D}\right.$, Lucien Baldas ${ }^{2, *}$ and Jürgen J. Brandner ${ }^{1, *(D)}$ \\ 1 Institute of Microstructure Technology, Campus Nord, Hermann-von-Helmholtz-Platz 1, \\ 76344 Eggenstein-Leopoldshafen, Germany; daniel.mariuta@kit.edu (D.M.); \\ arumugam_g@outlook.com (A.G.); jan.korvink@kit.edu (J.G.K.) \\ 2 Institut Clément Ader (ICA), Université de Toulouse, CNRS, INSA, ISAE-SUPAERO, Mines-Albi, UPS, \\ 31400 Toulouse, France; stephane.colin@insa-toulouse.fr (S.C.); christine.barrot@insa-toulouse.fr (C.B.) \\ 3 Université de Strasbourg, CNRS, ICPEES UMR 7515, F-67000 Strasbourg, France; slecalve@unistra.fr \\ 4 In'Air Solutions, 25 rue Becquerel, 67000 Strasbourg, France \\ * Correspondence: lucien.baldas@insa-toulouse.fr (L.B.); juergen.brandner@kit.edu (J.J.B.)
}

Received: 22 May 2020; Accepted: 9 July 2020; Published: 10 July 2020

\begin{abstract}
Formaldehyde ( $\mathrm{HCHO})$, a chemical compound used in the fabrication process of a broad range of household products, is present indoors as an airborne pollutant due to its high volatility caused by its low boiling point $\left(T=-19{ }^{\circ} \mathrm{C}\right)$. Miniaturization of analytical systems towards palm-held devices has the potential to provide more efficient and more sensitive tools for real-time monitoring of this hazardous air pollutant. This work presents the initial steps and results of the prototyping process towards on-chip integration of $\mathrm{HCHO}$ sensing, based on the Hantzsch reaction coupled to the fluorescence optical sensing methodology. This challenge was divided into two individually addressed problems: (1) efficient airborne $\mathrm{HCHO}$ trapping into a microfluidic context and (2) 3,5-diacetyl-1,4-dihydrolutidine (DDL) molecular sensing in low interrogation volumes. Part (2) was addressed in this paper by proposing, fabricating, and testing a fluorescence detection system based on an ultra-low light Complementary metal-oxide-semiconductor (CMOS) image sensor. Two three-layer fluidic cell configurations (quartz-SU-8-quartz and silicon-SU-8-quartz) were tested, with both possessing a $3.5 \mu \mathrm{L}$ interrogation volume. Finally, the CMOS-based fluorescence system proved the capability to detect an initial $10 \mu \mathrm{g} / \mathrm{L}$ formaldehyde concentration fully derivatized into DDL for both the quartz and silicon fluidic cells, but with a higher signal-to-noise ratio $(S N R)$ for the silicon fluidic cell $\left(S N R_{\text {silicon }}=6.1\right)$ when compared to the quartz fluidic cell $\left(S N R_{\text {quartz }}=4.9\right)$. The signal intensity enhancement in the silicon fluidic cell was mainly due to the silicon absorption coefficient at the excitation wavelength, $a\left(\lambda_{a b s}=420 \mathrm{~nm}\right)=5 \times 10^{4} \mathrm{~cm}^{-1}$, which is approximately five times higher than the absorption coefficient at the fluorescence emission wavelength, $a\left(\lambda_{e m}=515 \mathrm{~nm}\right)=9.25 \times 10^{3} \mathrm{~cm}^{-1}$.
\end{abstract}

Keywords: metal-oxide-semiconductor (CMOS)-based fluorescence sensing; light emitting diode (LED)-induced fluorescence; SU-8 2015 waveguide; silicon fluidic cell; 3,5-diacetyl-1,4-dihydrolutidine (DDL)

\section{Introduction}

Indoor air pollutant concentrations are known to be up to five times higher than outdoors. People generally spend $90 \%$ of their time indoors, and approximately 3.8 million people die yearly from diseases related to the exposure to indoor pollution [1]. Among all the indoor pollutants, volatile organic compounds (VOCs) are of particular interest due to their high levels 
of toxicity [2]. One of the VOCs that raises increased concern is formaldehyde (HCHO), an allergenic, mutagenic, and carcinogenic compound [3,4]. HCHO is largely used in the fabrication process of building materials, household products, and resins for wood products. There are ongoing research projects looking for a non-harmful $\mathrm{HCHO}$ alternative in the form of bio-based platform chemical 5-HMF (5-Hydroxymethylfurfural) [5], but meanwhile industrial consumption of HCHO is constantly increasing.

Indoor $\mathrm{HCHO}$ concentrations are up to fifteen times higher than those measured outdoors [6] and may have values ranging from 10 to $100 \mu \mathrm{g} / \mathrm{m}^{3}$ (1 to 82 parts-per-billion (ppb) at $25{ }^{\circ} \mathrm{C}$ and atmospheric pressure) [7]. The World Health Organization (WHO) standard for a safe daily exposure is set to $100 \mu \mathrm{g} / \mathrm{m}^{3}$ (82 ppb) concentration for a maximum period of $30 \mathrm{~min}$. In France, the recommendations are to limit the exposure to $30 \mu \mathrm{g} / \mathrm{m}^{3}$ ( $25 \mathrm{ppb}$ ), which will be reduced from 2023 onwards to $10 \mu \mathrm{g} / \mathrm{m}^{3}$ (8 ppb) [8,9]. The United States Environmental Protect Agency (US EPA) relies on a 2,4-dinitrophenylhydrazine (DNPH) tube sample followed by offline laboratory high-performance liquid chromatography (HPLC) analysis as the standard HCHO detection methodology [10]. This method exhibits the lowest detection limit of $0.048 \mu \mathrm{g} / \mathrm{m}^{3}(0.04 \mathrm{ppb})$, but it provides average concentrations over time intervals ranging from one hour to a week for both active and passive samplings, respectively $[9,10]$.

Alternative detection methods have been developed in order to enable real-time and in-field HCHO detection, such as proton transfer reaction mass spectrometry (PTR-MS) [11], gas chromatography mass spectrometry (GC-MS) [12], infrared diode laser spectroscopy [13,14], and Hantzsch reaction monitoring [15]. These methods rely on bulky instruments that are not or barely portable, and are, therefore, not compatible with indoor air monitoring. A device adapted for this need should be real-time, selective, palm-held, low-noise, battery-operated, and cost-effective [7,15].

Among the methods used for online HCHO sensing, the method based on the Hantzsch reaction coupled to fluorescence optical detection (see Figure 1a) is known as the most sensitive and selective $[10,15]$. The continuous detection methodology can be briefly described as a sequence of four steps: (1) air and reagent streaming; (2) HCHO trapping; (3) derivatization into a fluorescent compound; and (4) optofluidic fluorescence detection [9]. During step (1), the air and reagent phases are continuously put in contact, with the fluids being pressure-driven into the system using micropumps. During step (2), the HCHO molecules from the air are trapped in a 4-amino-3-penten-2-one (Fluoral-P) or acetylacetone solution. The molecular transfer from the gaseous phase to the liquid phase is characterized by a convection-diffusion mechanism [16]. The efficiency of the diffusion process is strictly related to a couple of parameters, such as the contacting area between the two phases, the contacting time, and the molecular driving forces across the gas-liquid interface (e.g., partial pressure difference, chemical potential, concentration difference) [17]. During step (3), a full derivatization process of the $\mathrm{HCHO}$ molecule into the 3,5-diacetyl-1,4-dihydrolutidine (DDL) fluorescent molecule takes place for a residence time of $t=3 \mathrm{~min}$ at $T=65^{\circ} \mathrm{C}$ (see Figure 1b).

Some works related to on-chip optofluidic integration of HCHO detection in either food [18-20], Chinese herbs [21], or indoor air [7,22] have recently been reported. A microfluidic paper-based analytical device ( $\mu \mathrm{PAD}$ ) was proposed by Guzman et al. [18] for detection of low $\mathrm{HCHO}$ concentrations in food. The detection was made using a complementary metal-oxide-semiconductor (CMOS) camera and the concentration was found by interpreting the images based on RGB color analysis software on a smartphone. The detection mechanism worked offline and the formaldehyde detection range of the device was $0.2-2.5 \mathrm{mg} / \mathrm{L}$. Improvements in terms of portability, response time, and detection range of $0-0.8 \mathrm{mg} / \mathrm{L}$ for this system was presented by Liu et al. [19]. Weng et al. [20] integrated four reaction reservoirs and one substrate reservoir on a polydimethylsiloxane (PDMS) microfluidic chip, enabling $\mathrm{HCHO}$ detection based on the absorption spectroscopy in $2 \mu \mathrm{L}$ food samples. A three-layer poly (methyl methacrylate) (PMMA) device with a detection range of $1-50 \mathrm{mg} / \mathrm{L}$ was presented by Liu et al. [21] for the detection of $\mathrm{HCHO}$ concentrations in Chinese herbs; it was based on laser-induced fluorescence. 


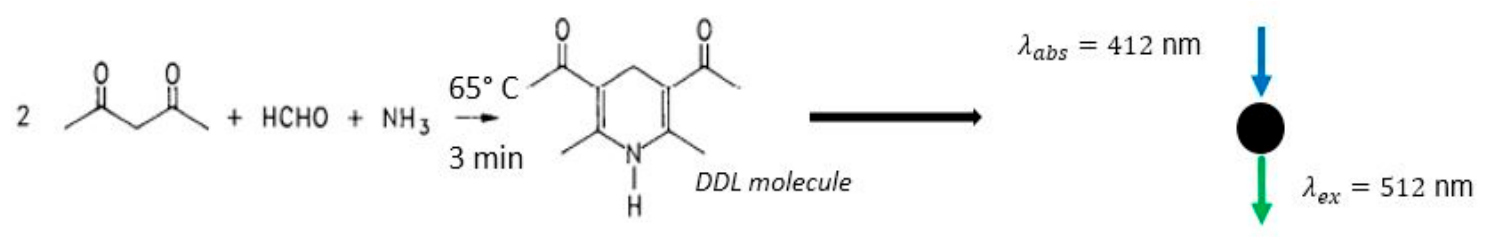

(a)

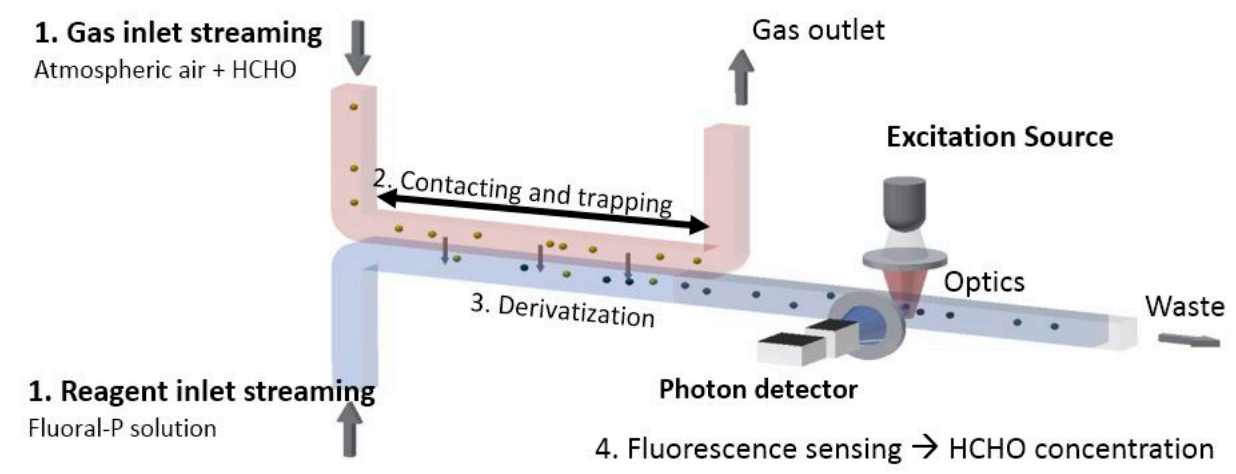

(b)

Figure 1. Formaldehyde $(\mathrm{HCHO})$ detection methodology. (a) Chemical derivatization reaction of formaldehyde into 3,5-diacetyl-1,4-dihydrolutidine (DDL). (b) Gas-liquid contacting, trapping, and detection scheme.

A microfluidic lab-on-a-chip derivatization technique based on the GC-MS measurement technique for $\mathrm{HCHO}$ indoor air sensing was described by Pang et al. [22]. The method relied on a glass Pyrex microreactor with a $2.0 \mathrm{~m}$ long and $620 \mu \mathrm{m}$ internal diameter round microchannel as a reactor. The reaction of $\mathrm{HCHO}$ with two reagents (pentafluorophenyl hydrazine and O-(2,3,4,5,6-pentafluorobenzyl) hydroxylamine) was studied in a microfluidic context, with the system achieving continuous sampling and analysis with a time resolution of $30 \mathrm{~min}$ and a limit of detection (LOD) down to $1.2 \mu \mathrm{g} / \mathrm{m}^{3}$ (1 ppb). The reagent flow rates were varied between 20 and $120 \mu \mathrm{L} / \mathrm{min}$, while the maximum operating temperature and pressure were $T=300^{\circ} \mathrm{C}$ and $p=3 \mathrm{MPa}$, respectively. Despite the evident advantages of low reactant flow rates, the operating parameters and the time resolution were too high to be compatible with the previously mentioned performances of a HCHO palm-held detector.

Becker et al. [7] developed a microfluidic analytical device $(20 \mathrm{~cm} \times 25 \mathrm{~cm} \times 15 \mathrm{~cm})$ dedicated to air analysis based on the Hantzsch reaction, which reached a LOD of $0.13 \mu \mathrm{g} / \mathrm{m}^{3}(0.1 \mathrm{ppb})$ for a $17 \mu \mathrm{L} / \mathrm{min}$ reagent flow rate in a microporous tube $(10.0 \mathrm{~cm}$ length, $0.9 \mathrm{~mm}$ internal diameter). The porous tube was placed in a gas microchamber fueled with gaseous $\mathrm{HCHO}$ at a flow rate of $250 \mathrm{NmL} / \mathrm{min}$. The temporal resolution was $2 \mathrm{~s}$ and the response time was $15 \mathrm{~min}$, enabling near-real-time detection on a portable device. The system performance might be enhanced by simplifying the fluorescence detection system based on a photomultiplier tube (PMT) detector and by reducing the interrogation volume.

Even if the Hantzsch-reaction-based method relies on "wet chemistry", involving a continuous reagent consumption, this method is currently one of the most reliable candidates for developing a sensitive palm-held continuous detector. The alternatives to the wet-chemistry-based methods are electrochemical detection methods. The recently developed electrochemical sensors, despite their rapid response, operate at very high temperatures, are not energy efficient, and cannot be deployed in atmospheres with flammable potential [23]. Their main disadvantages are their low sensitivity and the absence of selectivity; other aldehydes and gas pollutants can interfere with the formaldehyde measurements, as observed by Baldelli et al. [24]. 
Thus, the aim of developing a palm-held sensitive continuous detector could be achieved by exploiting the recent advancements in the fields of microfluidics, optofluidics (combining microfluidics and optics), microfabrication, and integrated system technology. On-chip integration of microfluidic analytical applications poses multidisciplinary challenges, generally related to: (1) fluid-fluid interactions; (2) fluid-structure interactions; (3) microstructure fabrication; and (4) system integration.

This work presents the preliminary steps and results of the prototyping process towards on-chip integration of an $\mathrm{HCHO}$ sensing system. This challenge was split into two individually addressed problems: (1) efficient airborne HCHO trapping in a microfluidic context and (2) low-concentration DDL molecular sensing in reduced interrogation volumes. Problem (1) was partially addressed and a gas-liquid microreactor concept was built around a disposable membrane-based PMMA flat contactor [16]. Problem (2) was addressed by proposing, fabricating, and testing a fluorescence detection system based on an ultrasensitive CMOS image sensor. Two three-layer fluidic cell configurations (quartz-SU-8-quartz and silicon-SU-8-quartz) were tested, with both possessing a $3.5 \mu \mathrm{L}$ interrogation volume.

\section{Materials and Methods}

The fluorescence phenomenon is largely used for molecular optical sensing in microfluidic analytical applications due to its selectivity and capability to reach low detection limits, including single-molecule detection $[25,26]$. Fluorescence is the property of a molecule allowing it, once excited by light at a specific wavelength $\lambda_{a b s}$, to emit light after some nanoseconds at a longer wavelength $\lambda_{e m}$, a behavior known as the Stokes shift. A fluorescent molecule is characterized by the quantum yield $\phi$, defined as the ratio of the number of emitted photons to the number of absorbed photons. The number of photons emitted by fluorescence is usually up to three orders of magnitude less than the number of photons being absorbed to excite the molecule [27].

The amount of fluid involved in microfluidic systems is, by definition, reduced. Therefore, the emitted fluorescence signal in optofluidic sensors is very low. Traditional fluorescence detection systems use a complex optical path involving a system of lenses, a high-performance light source, and very sensitive photon detector to capture the low-intensity fluorescence signals [28]. Mainly due to these reasons, the systems are generally expensive, bulky, and barely portable in the best scenarios.

Miniaturization of fluorescence sensing optofluidic devices is a field currently experiencing intense research activity aiming to identify fabrication and design methodologies for an ultraportable, monolithic, and multiplexing sensing architecture. Advances in micro- and nanofabrication technologies have been used to develop new design strategies in order to maximize the detection while shrinking dimensions.

Therefore, when the design of an analytical microsystem based on fluorescence detection is attempted, the Stokes shift and the quantum yield of the molecule are fundamental prerequisites to be considered in order to properly identify the most suitable detection scheme, filtration elements, and light detector. The noise sources in optofluidic fluorescence-based sensors originate from both optical (shot and flicker components) and non-optical elements (dark noise of the detector) [29]. The optical background noise may originate from components with different spectra, e.g., other fluorophores, scattering light, and autofluorescence.

The DDL molecule has two absorption peaks: one in the ultraviolet (UV) range at the $255 \mathrm{~nm}$ wavelength and the other in the visible spectrum range at $\lambda_{a b s}=412 \mathrm{~nm}$, while the fluorescence emission peak occurs at $\lambda_{e m}=515 \mathrm{~nm}$, with a very low quantum yield $\phi\left(20^{\circ} \mathrm{C}\right)=0.005$ [30]. The shorter wavelength possesses a better fluorescence yield but a higher background signal. The absorption peak located at $\lambda_{a b s}=412 \mathrm{~nm}$ was chosen for this prototype, since the UV light sources are more health damaging and less efficient from a cost perspective when compared to the violet light sources. 


\subsection{Complementary Metal-Oxide-Semiconductor (CMOS)-Based Fluorescence Detector: Sensor Design and Fabrication}

The concept of the optical detection system proposed in this work for the detection of the DDL molecules combined a couple of principles usually used in optofluidic sensing microsystems (see Figure 2). The design was based on an orthogonal detection scheme with a CMOS image sensor as the photon detector and high-power light emitting diodes (HP-LEDs) as excitation sources. A square band pass filter was selected and placed in between the fluidic cell and the CMOS image sensor. The components of both optical and fluidic circuits were hosted by two 3D-printed (Ultimaker 3 printer, Utrecht, The Netherlands) holders, named the upper and lower holders.

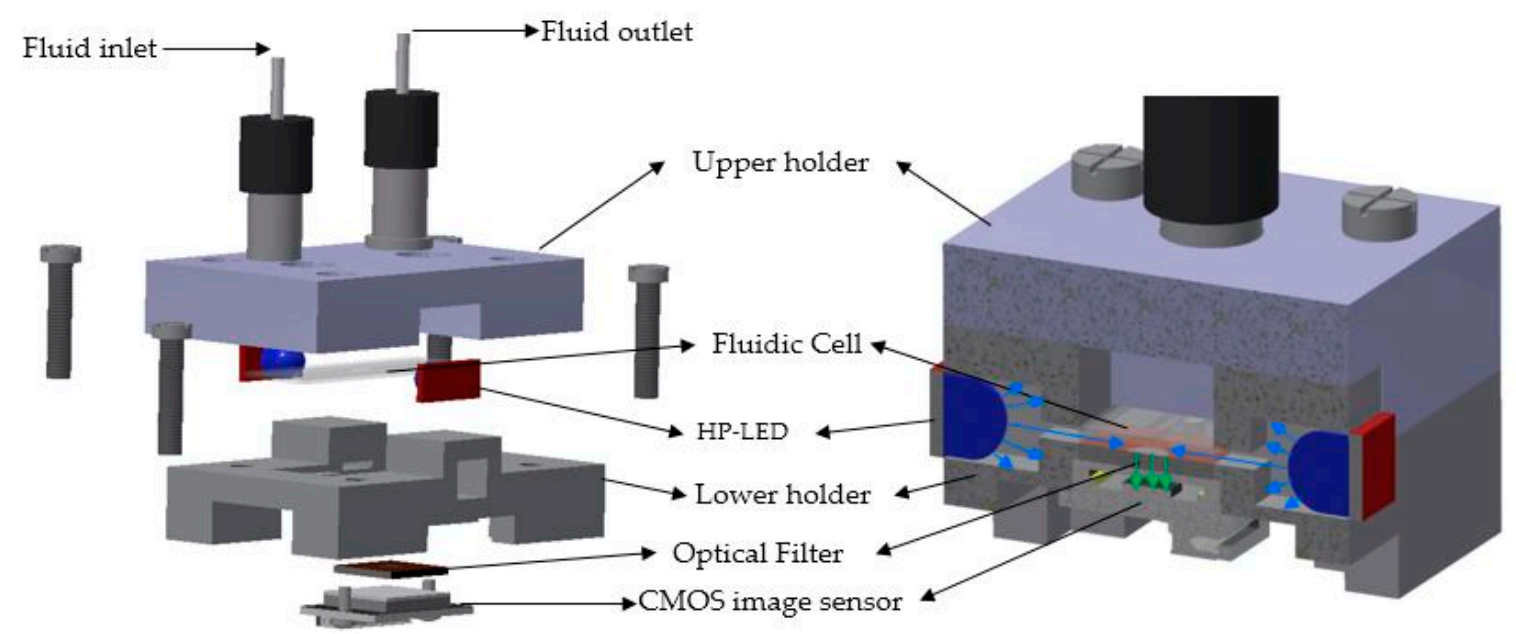

(a)

(b)

Figure 2. The concept of the complementary metal-oxide-semiconductor (CMOS)-based fluorescence detector $(46 \mathrm{~mm} \times 30 \mathrm{~mm} \times 10 \mathrm{~mm}$ ). (a) Exploded view of the detector. (b) Transversal cross-section of the assembled sensing device.

The particularity of this design relied on the orthogonal illumination scheme implemented in combination with the contact sensing principle. The contact sensing principle involves the photon detector, the filtration component (if it exists), and the fluidic cell being in direct contact. This is advantageous, since the optical path from the fluorescence source up to the photon detector is diminished, i.e., the optical loss is lower.

\subsubsection{Microfluidic Circuit}

The fluidic system comprised the fluidic cell, the N-333 type connectors (IDEX Health and Science LLC, Rohnert Park, CA, USA), and the fluidic capillaries. The connectors were integrated into the upper holder. When the upper and lower holders were held together through the four screws, a leakage-free fluidic circuit was obtained, with an important role being played by the rubber sealing of the connectors.

The fluidic cell, i.e., the element of the system hosting the microfluidic flow and the detection chamber from where the fluorescence signal is collected, was designed as a three-layer structure (Figure 3c) and fabricated using well-established photolithography techniques (Figure 3b,d,e).

Two fluidic cell configurations were fabricated, with the difference between the two consisting in the nature of the material of the upper layer. For the first configuration a quartz-SU-8 2015 negative photoresist-quartz structure (quartz fluidic cell) was employed, while for the second configuration a silicon-SU-8 2015 negative photoresist-quartz structure (silicon fluidic cell) was employed.

Quartz was selected due to its low autofluorescence emissions [31], this material being largely used for the fabrication of commercial flow-through fluidic cells. Silicon, a material largely used in the fabrication process of chip technology, possesses interesting properties for the particular aim of 
this project. More precisely, the absorption coefficient of silicon at the LED emission wavelength, $a\left(\lambda_{a b s}=420 \mathrm{~nm}\right)=5 \times 10^{4} \mathrm{~cm}^{-1}$, is approximately five times higher than the absorption coefficient at the emission wavelength, $a\left(\lambda_{e m}=515 \mathrm{~nm}\right)=9.25 \times 10^{3} \mathrm{~cm}^{-1}$ [32]. Therefore, the absorption of the excitation light in silicon, which contributes to the optical background noise, is expected to be larger than the absorption of the fluorescence emission, producing an enhancement of the detection limit of the system.

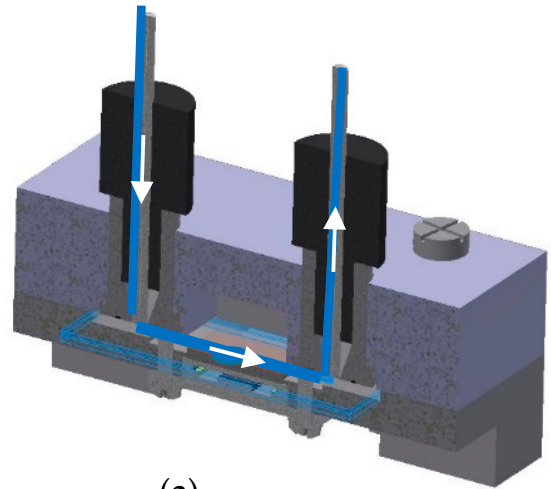

(a)

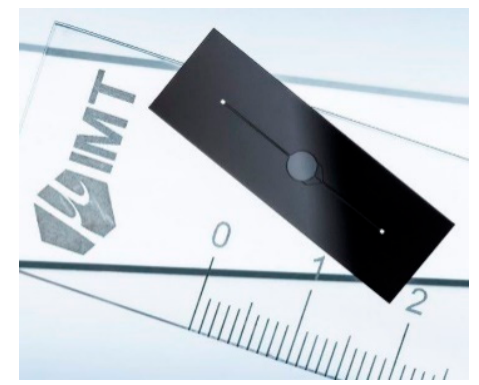

(b)
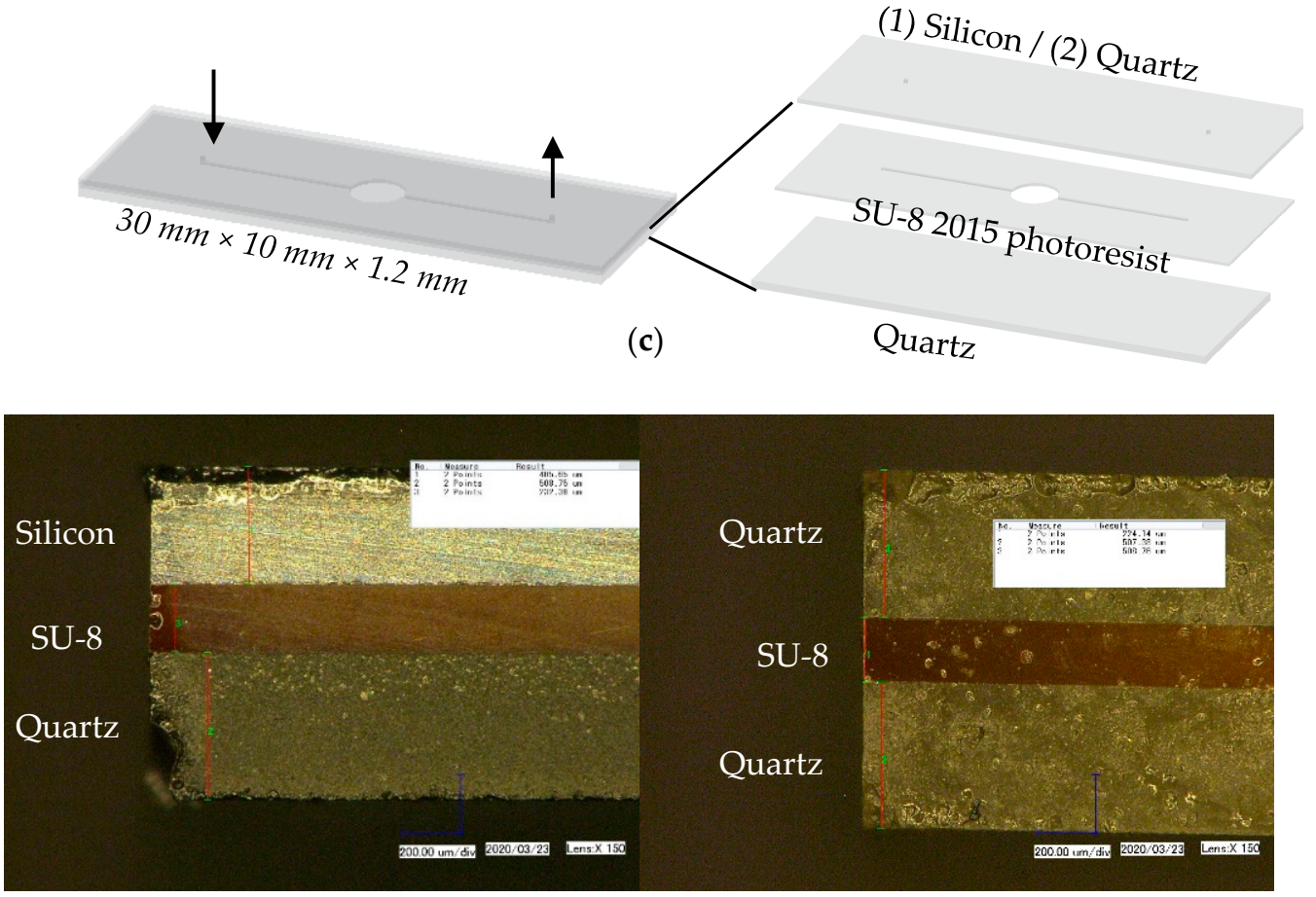

(d)

(e)

Figure 3. (a) Microfluidic circuit of the detection system. (b) Fabricated silicon fluidic cell. (c) Fluidic cell concept. (d) Microscope view of silicon $(405 \mu \mathrm{m})$-SU-8 $(232 \mu \mathrm{m})$-quartz $(508 \mu \mathrm{m})$ fluidic cell cross-section. (e) Microscope view of quartz $(507 \mu \mathrm{m})-\mathrm{SU}-8(224 \mu \mathrm{m})$-quartz $(508 \mu \mathrm{m})$ fluidic cell cross-section.

The fluidic cell (Figure 3b,d,e) was fabricated at the Laboratoire d'Analyse et d'Architecture des Systèmes (LAAS), Toulouse, France. A 4 inch $500 \mu \mathrm{m}$ AF32 quartz wafer (Schott AG, Mainz, Germany) was initially cleaned with oxygen plasma at power $P=800 \mathrm{~W}$ for $t=5 \mathrm{~min}$, followed by the deposition of a $200 \mu \mathrm{m}$ SU-8 2015 negative photoresist layer (Kayaku Advanced Materials, Westborough, MA, USA) and baking using an EVG 120 machine (EVG, St. Florian am Inn, Austria). Afterwards, a mask was placed on top of the SU-8 layer, allowing UV light exposure using a Suss MA6 gen4 instrument (SÜSS MICROTEC SE, Garching, Germany) $\left(\lambda=365 \mathrm{~nm}, t=42 \mathrm{~s}\right.$, power density $\left.P_{d}=14 \mathrm{~mW} / \mathrm{cm}^{2}\right)$ 
in order to create the desired channeling geometry, with a uniform $200 \mu \mathrm{m}$ depth. Next, the structure was washed using an SU-8 developer to remove the exposed parts, then hard-baked $\left(T=125{ }^{\circ} \mathrm{C}\right.$, $t=1 \mathrm{~min}$ ). The fluidic inlet and outlet were created through a piercing process on a second $500 \mu \mathrm{m}$ quartz wafer. Initially, the quartz wafer was coated with Photec 2040 dry film (Hitachi Chemical, Tokyo, Japan) to protect the structure during the piercing process. The piercing was done by sandblasting, followed by rinsing and cleaning with acetone and deionized water. Then, the same oxygen plasma $(P=800 \mathrm{~W}, t=5 \mathrm{~min})$ cleaning procedure used for the first quartz wafer was repeated for the second one. An additional $10 \mu \mathrm{m}$ SU-8 2015 negative photoresist layer was required on one side of the wafer to facilitate the bonding with the SU-8 2015 layer from the first wafer. Once this layer was coated, the two wafers were bonded using Nanonex NX Nanoimprint equipment (Nanonex, Monmouth Junction, NJ, USA) by applying uniform pressure on both sides. A dicing protection layer made of AZ 4562 photoresist layer (Microchemicals $\mathrm{GmbH}$, Ulm, Germany) was coated and six fluidic cells were finally obtained with different interrogation volumes, as described by Mariuta et al. [33]. The geometry of the detection chamber (Figure 3c) was optimized using a computational fluid dynamics (CFD) model in Ansys Fluent to avoid fluid stagnation regions or dead volumes [33] and to match the sensing area $\left(4.8 \times 4.8 \mathrm{~mm}^{2}\right)$ of the photon detector.

\subsubsection{Optical Circuit}

The optical circuit of the sensing system relies on (see Figure 4): (1) the excitation light source; (2) the waveguide (SU-8 2015 negative photoresist layer); (3) the band pass filter; and (4) the CMOS image sensor.

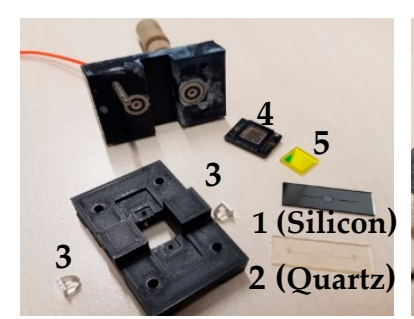

(a)

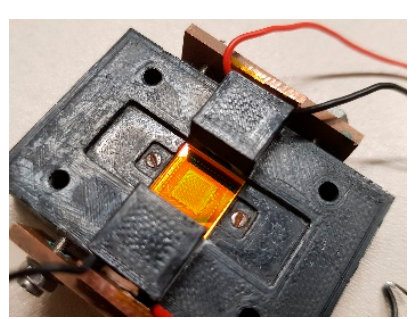

(b)

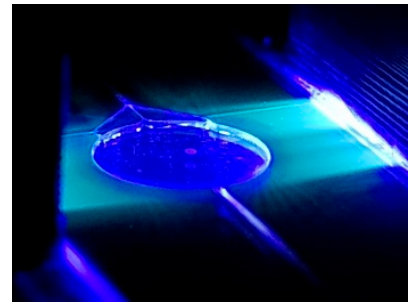

(c)

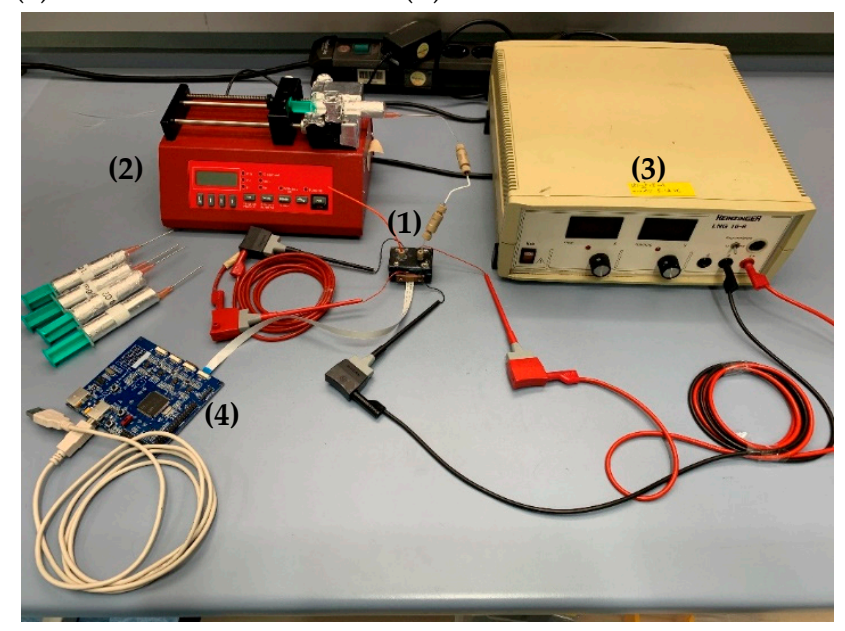

(d)

Figure 4. (a) Exploded view of the detection system before assemblage: (1) silicon fluidic cell; (2) quartz fluidic cell; (3) $420 \mathrm{~nm}$ light emitting diodes (LEDs); (4) CMOS image sensor; (5) band pass filter. (b) Assembled device;.(c) Light transmission through the fluidic cell towards the detection chamber. (d) (1) Experimental setup: assembled device, (2) syringe pump, (3) 24 V DC power supply, (4) microcontroller board. 
LEDs are currently the most widespread excitation choice in microfluidic chemical sensors [34]. The current LEDs available on the market are high-power devices and are relatively cost-efficient. The main disadvantage of the LEDs when they are considered in optical sensing applications is related to the incoherence of the light beam, for which lasers perform better. LEDs are commercially available in the 210-3800 nm spectral range, with their emission spectrum being compatible with the molecules' fluorescence excitation bands [34]. A SMB1N-420H-02 LED (Roithner Lasertechnik GmbH, Vienna, Austria) was selected for this prototype, with a maximal optical radiation power $P_{L E D}=420 \mathrm{~mW}$ at $\lambda_{L E D}=420 \mathrm{~nm}$ emission wavelength, viewing angle of $22^{\circ}$, with the maximum intensity concentrated at the center of its dispersion range. Two LEDs illuminated the detection chamber (see Figure 4a,b), considering its high diameter-over-depth ratio (23.5), to make sure that the excitation photons entirely penetrated the bulk of the interrogation volume.

Photomultiplier tubes (PMT), silicon photodiodes (SPD), CMOS image sensors, and more recently organic photodiodes (OPD) are photon detectors used in the miniaturization of fluorescence-based sensing devices. The recent evolution of the CMOS technology has introduced advantages, such as reduced dimensions, high sensitivity, coupling with filtration algorithms, very low prices per unit, low power consumption, and integrated signal processing, making it compatible for the miniaturization of fluorescence detection. On-chip CMOS integration, coupled with microfluidics for detection at the microscale, has increasingly been investigated in the recent literature [28,35-37], especially for the development of filterless prototypes.

A ULS24 (Anitoa Systems LLC, Menlo Park, CA, USA) CMOS image sensor model was selected as the photon detector for the current prototype, due to its ultra-low light sensitivity $\left(3 \times 10^{-4} \mathrm{lux}\right)$, low-power supply $(3.3 \mathrm{~V} / 1.8 \mathrm{~V}, 30 \mathrm{~mW})$, maximum sensitivity $(60 \%)$ at $\lambda_{e m}=515 \mathrm{~nm}$, and minimum sensitivity $(40 \%)$ at $\lambda_{a b s}=420 \mathrm{~nm}$. The CMOS image sensor was fabricated on a $0.18 \mu \mathrm{m}$ CIS instrument with a die size of $4.8 \times 4.8 \mathrm{~mm}^{2}$. The implemented "intelligent dark current management" algorithm made this image sensor capable of matching the sensitivity of the cooled charged-coupled device (CCD) and PMT technologies currently available on the market [38].

The transmission efficiency of the $540 \pm 60 \mathrm{~nm}$ band pass filter, model BP525-R10, $1 \mathrm{~mm}$ thickness (Midwest Optical Systems, Palatine, IL, USA), was tested using a Perkinelmer Lambda 950 UV/VIS spectrometer (PerkinElmer, Waltham, MA, USA). It was found that the transmission efficiency was $0.01 \%$ at the excitation wavelength and $91.35 \%$ at the emission wavelength (see Figure 5). On top of the band pass filter, was placed a thin metallic layer $(200 \mu \mathrm{m})$ with a central circular slit of $4.8 \mathrm{~mm}$ diameter in order to further minimize the amount of light and then reduce the optical noise induced by the excitation light reaching the CMOS photon detector.
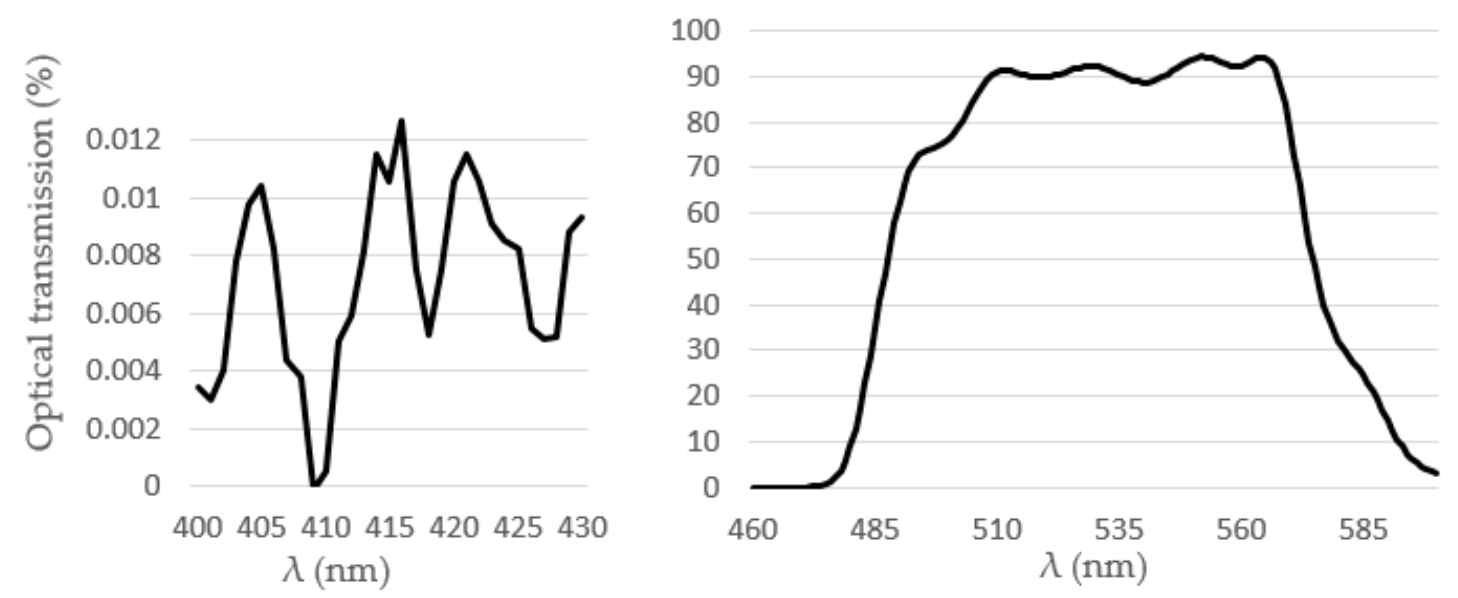

Figure 5. Optical transmittance of the band pass filter. 


\subsection{CMOS-Based Fluorescence Detector: Experimental Set-Up}

\subsubsection{Chemicals and Reagents}

The Fluoral-P (0.01 M) was prepared by mixing $0.3 \mathrm{~mL}$ of acetic acid 100\% (Merck, Molsheim, France), $0.2 \mathrm{~mL}$ of acetylacetone $99 \%$ (Merck), and $15.4 \mathrm{~g}$ of ammonium acetate $98 \%$ (Sigma-Aldrich, Lyon, France) in $200 \mathrm{~mL} 18.2 \mathrm{M} \Omega \mathrm{cm}$ Milli-Q water at $25{ }^{\circ} \mathrm{C}$ (Millipore, Molsheim, France). The formaldehyde solutions $\left(c_{1}=0.02 \mathrm{mg} / \mathrm{L}, c_{2}=0.2 \mathrm{mg} / \mathrm{L}, c_{3}=2 \mathrm{mg} / \mathrm{L}, c_{4}=20 \mathrm{mg} / \mathrm{L}\right)$ were prepared at the Institute of Chemistry and Processes for Energy, Environment and Health (ICPEES) Strasbourg by mixing a commercial formaldehyde solution (37\% in water, Sigma-Aldrich) with Mili-Q water $\left(18.2 \mathrm{M} \Omega \cdot \mathrm{cm}\right.$ at $25{ }^{\circ} \mathrm{C}$, Millipore). DDL solutions containing initial formaldehyde concentrations $\left(\mathrm{c}_{1}=0.01 \mathrm{mg} / \mathrm{L}, \mathrm{c}_{2}=0.1 \mathrm{mg} / \mathrm{L}, \mathrm{c}_{3}=1.0 \mathrm{mg} / \mathrm{L}, \mathrm{c}_{4}=10.0 \mathrm{mg} / \mathrm{L}\right)$ were prepared just before the measurements by mixing Fluoral-P $(0.02 \mathrm{M})$ and formaldehyde solutions $(1: 1 \mathrm{v} / \mathrm{v})$, then placing it these an oven at $T=65^{\circ} \mathrm{C}$ for $t=3 \mathrm{~min}$ to fully derivatize formaldehyde into DDL.

\subsubsection{Experimental Procedure}

The two LEDs were connected in series, with the power being supplied from a $24 \mathrm{~V}$ DC source. The LEDs were turned on for short periods $(t \cong 1 \mathrm{~s})$, while the data from the CMOS image sensor were captured using a PC interface during this activation time of the excitation source. Heat can cause a shift in the LED emission band, reducing the detection accuracy. Thus, the illumination of the detection chamber was done in short pulses $(t \cong 1 \mathrm{~s})$ in order to avoid a temperature increase of the LEDs, which were provided with flat copper heat sinks. The interface provided a $12 \times 12$ matrix, representing the photon counts measured by each pixel, the temperature of the CMOS sensor at the measurement time, and a mean value $\bar{X}$ representing the average of all the $X_{i} 12 \times 12$ photon counts.

The ULS 24 CMOS image sensor was connected to the microcontroller board (Anitoa Systems LLC, Menlo Park, CA, USA), then to a personal computer (Figure 4d). The CMOS image sensor was settled to work in low-gain mode, $12 \times 12$-pixel configuration, and $t=1 \mathrm{~ms}$ integration time.

The response of the system was iteratively tested for different DDL solutions at various formaldehyde concentrations $\left(c_{1}=0.01 \mathrm{mg} / \mathrm{L}, c_{2}=0.1 \mathrm{mg} / \mathrm{L}, c_{3}=1.0 \mathrm{mg} / \mathrm{L}, c_{4}=10.0 \mathrm{mg} / \mathrm{L}\right.$, and for the blank concentration $\left.c_{0}=0.0 \mathrm{mg} / \mathrm{L}\right)$. During the measurement process, three different optical powers of the LED were employed: $P_{1}=0.25 P_{L E D}=105 \mathrm{~mW}, P_{2}=0.5 P_{L E D}=210 \mathrm{~mW}$, $P_{3}=0.75 P_{L E D}=315 \mathrm{~mW}$. The DDL solutions were continuously sampled during the measurements at a flow rate of $10 \mu \mathrm{L} / \mathrm{min}$.

\section{Results and Discussion}

The experimental response of the system was evaluated by applying a regression analysis technique to the experimental data obtained from two independently prepared DDL samples $(N=2$, sample \#1 and sample \#2) for each of the tested concentrations, $c_{i, i}=0, \ldots .4$. Each of the samples processed in the system was analyzed by taking seven continuous measurements $(n=7)$ of the photon intensities, represented by $X_{i, i=1, \ldots, 7}$ in Equation (1). $X_{i}$ was in fact the mean value of all photon intensities given by the $12 \times 12$ pixel matrix obtained at the particular measurement time. Here, $\bar{X}_{\# 1}$ represented the mean value of the $X_{i, i=1, \ldots, 7}$ measurements taken for the first sample, while $\bar{X}_{\# 2}$ represented the mean value for the second sample investigated at a specific formaldehyde concentration of DDL solution (see Tables 1 and 2).

The precision of the evaluation was quantified by calculating the absolute $(\sigma)$ (Equation (1)) and relative standard deviations (RSD) (Equation (2)), and the performance was estimated using the signal-to-noise ratio (SNR) (Equation (3)). The SNR was used to describe the signal increase relative to the blank sample response $\left(c_{0}=0.0 \mathrm{mg} / \mathrm{L}\right)$, but its relevance was limited due to the low number of independent samples tested. While $\sigma_{\# 1}$ and $\sigma_{\# 2}$ represented the standard deviations obtained for 
measurements taken for similar samples $\left(\bar{X}_{\# 1}\right.$ and $\left.\bar{X}_{\# 2}\right), \sigma$ represented the standard deviation of $\bar{X}_{N=2}=\left(\bar{X}_{\# 1}+\bar{X}_{\# 2}\right) / 2$ values.

$$
\begin{gathered}
\sigma=\sqrt{\frac{\sum_{i=1}^{n}\left(X_{i}-\bar{X}\right)}{N}} \text {, with } \bar{X}=\frac{1}{n} \sum_{i=1}^{n} X_{i} \\
R S D=\frac{\sigma}{\bar{X}_{N=2}} \\
\operatorname{SNR}\left(c_{i}\right)=\frac{\bar{X}_{N=2}\left(c_{i}\right)-\bar{X}\left(c_{0}\right)}{\sigma\left(c_{i}\right)}
\end{gathered}
$$

Memory effects (see Figure 6) were observed during the initial stages of the experimental campaign. Therefore, the fluidic cells were rinsed with acetone and dried in the oven after each sampling.

Table 1. Error distribution as the standard deviation $(\sigma)$, relative standard deviation (RSD), and the signal-to-noise ratio (SNR) for the quartz fluidic cell at the excitation optical power, $P=315 \mathrm{~mW}$, where \#1 and \#2 represented the two independently prepared samples for each of the tested formaldehyde concentrations $c_{i}$ for $i=0, \ldots, 4$.

\begin{tabular}{cccccc}
\hline Formaldehyde Concentration $(\mathbf{m g} / \mathbf{L})$ & $\mathbf{0 . 0 0}$ & $\mathbf{0 . 0 1}$ & $\mathbf{0 . 1 0}$ & $\mathbf{1 . 0}$ & $\mathbf{1 0 . 0}$ \\
\hline $\bar{X}_{\# 1}$ (counts) & 1122 & 1477 & 1505 & 1528 & 1611 \\
$\sigma_{\# 1}$ & 3 & 2 & 3 & 4 & 5 \\
$R S D_{\# 1}(\%)$ & 0.21 & 0.16 & 0.21 & 0.29 & 0.29 \\
$\bar{X}_{\# 2}$ (counts) & 1155 & 1230 & 1323 & 1489 & 1546 \\
$\sigma_{\# 2}$ & 3 & 9 & 2 & 1 & 3 \\
$R S D_{\# 2}(\%)$ & 0.24 & 0.71 & 0.16 & 0.06 & 0.20 \\
$\bar{X}_{N}=2($ counts) & 1189 & 1354 & 1414 & 1509 & 1578 \\
$\bar{X}_{N=2}$ & 34 & 123 & 91 & 20 & 33 \\
$R S D(\%)$ & 2.82 & 9.11 & 6.43 & 1.29 & 2.06 \\
$S N R$ & - & 4.9 & 6.7 & 9.6 & 11.6 \\
\hline
\end{tabular}

Table 2. Error distribution as the standard deviation $(\sigma)$, relative standard deviation (RSD), and signal-to-noise ratio (SNR) for the silicon fluidic cell at the excitation optical power $P=315 \mathrm{~mW}$, where \#1 and \#2 represented the two independently prepared samples for each of the tested concentrations $c_{i}$ for $i=0, \ldots, 4$.

\begin{tabular}{cccccc}
\hline Formaldehyde Concentration $(\mathbf{m g} / \mathbf{L})$ & $\mathbf{0 . 0 0}$ & $\mathbf{0 . 0 1}$ & $\mathbf{0 . 1}$ & $\mathbf{1 . 0}$ & $\mathbf{1 0}$ \\
\hline $\bar{X}_{1}$ (counts) & 771 & 902 & 988 & 966 & 1,018 \\
$\sigma_{\# 1}$ & 3 & 1 & 2 & 15 & 2 \\
$R S D_{\# 1}(\%)$ & 0.36 & 0.15 & 0.24 & 1.59 & 0.22 \\
$\bar{X}_{2}$ (counts) & 822 & 1005 & 1066 & 1053 & 1184 \\
$\sigma_{\# 2}$ & 4 & 8 & 2 & 2 & 1 \\
$R S D_{\# 2}(\%)$ & 0.44 & 0.75 & 0.21 & 0.16 & 0.09 \\
$\bar{X}_{N}=2$ counts) & 797 & 954 & 1027 & 1010 & 1101 \\
$\bar{X}_{N=2}$ & 26 & 51 & 39 & 43 & 83 \\
$R S D(\%)$ & 3.21 & 5.39 & 3.82 & 4.27 & 7.54 \\
$S N R$ & - & 6.1 & 9.0 & 8.3 & 11.9 \\
\hline
\end{tabular}

The response of the CMOS-based fluorescence detector for a blank sample ( $\left.c_{0}=0.00 \mathrm{mg} / \mathrm{L}\right) \mathrm{was}$ plotted in Figure $7 \mathrm{~b}$. By increasing the excitation optical power, a perfect linear response $(R 2=0.999)$ was obtained for both quartz $(y=351.5 x+141)$ and silicon $(y=226.5 x+120.3)$ cells. However, a higher steepness of the linear equation was observed for the quartz fluidic cell compared to the silicon fluidic cell. Moreover, lower values of the photon counts were measured for the silicon cell. The lower intensity and steepness measured for the silicon cell may have been caused by two main factors: (1) 
lower excitation light intensity reaching the detection chamber, and consequently the photon detector, due to the $400 \mu \mathrm{m}$ thickness of the opaque silicon upper layer; (2) the light absorbance of silicon at $\lambda_{a b s}=420 \mathrm{~nm}$ is approximately five times higher than the absorbance of silicon at $\lambda_{e m}=515 \mathrm{~nm}$. This latter factor might also explain the differences between the SNRs obtained for the two fluidic cell configurations (see Tables 1 and 2, Figure 7a). Analyzing the results obtained for both fluidic cells (Figure $8 b, c)$, it was observed that the fluorescence intensity measured for the silicon cell was generally lower compared to that of the quartz cell.

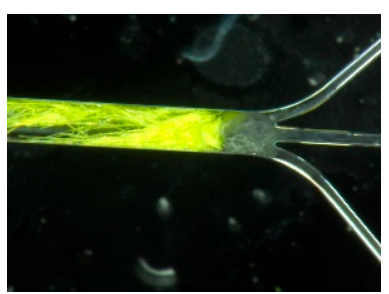

(a)

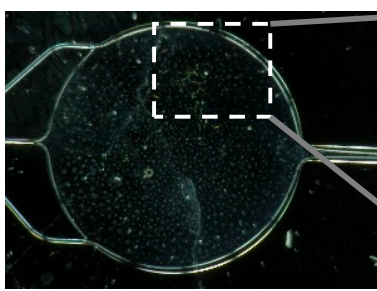

(b)

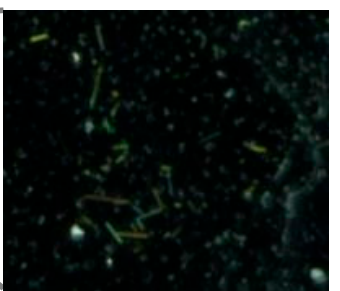

(c)

Figure 6. (a) Dry green DDL crystals cluster after streaming a DDL solution at a formaldehyde concentration of $c_{5}=100 \mathrm{mg} / \mathrm{L}$. (b) Detection chamber with (c) green DDL crystals on the inner walls after use of the DDL solution at a formaldehyde concentration of $c_{4}=10 \mathrm{mg} / \mathrm{L}$.

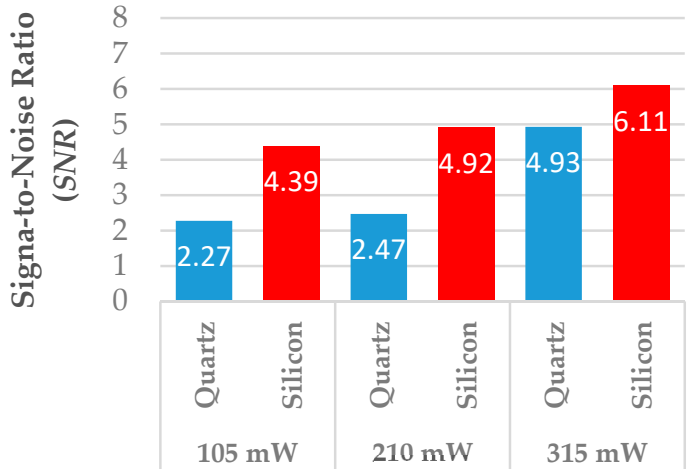

(a)

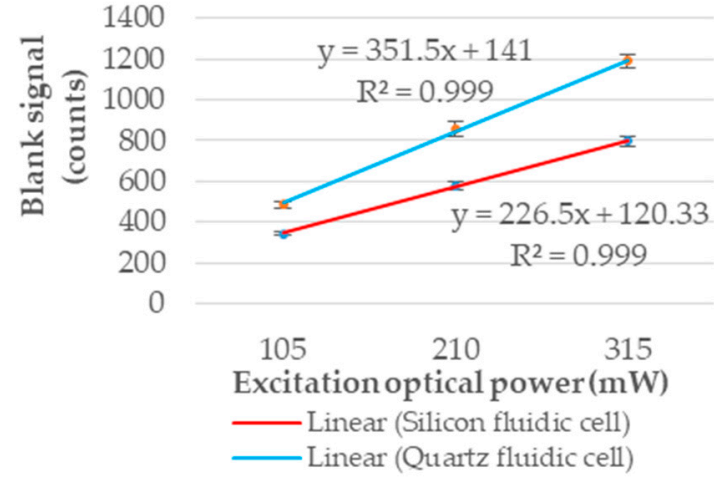

(b)

Figure 7. (a) Signal-to-noise ratios (SNRs) obtained for quartz and silicon fluidic cells at a formaldehyde concentration of $c_{1}=0.01 \mathrm{mg} / \mathrm{L}$ in DDL solution and with different optical powers. (b) The linear response obtained for three excitation optical powers at $c_{0}=0.00 \mathrm{mg} / \mathrm{L}$ (blank sample). The error bars indicate the standard deviations for two independently prepared samples $(N=2)$.

From the presented experimental dataset, relatively high values of the photon counts were observed for the blank sample (see Figure $7 \mathrm{~b}$ ). This was mainly due to the fact that the transmission efficiency of the band pass filter at the excitation wavelength was not exactly zero (see Figure 4). This fact caused $0.008 \%$ of the excitation optical signal to reach the very sensitive ULS24 CMOS image sensor.

The CMOS image sensor response as a $12 \times 12$ light intensity matrix representation is illustrated in Figure 8a. The image corresponding to the CMOS dark noise depicted its response in a complete dark environment (no excitation light). The second picture from the left to the right illustrated the CMOS image sensor response for a $0.0 \mathrm{mg} / \mathrm{L}$ concentration solution (blank sample), with a value of 1225 counts being registered. As expected, higher values were obtained once the DDL concentration streamed into the system was iteratively increased. Due to the fact that the differences between the pixel outputs were relatively low compared to the dynamic range of the image sensor, the gray color gradient found was also low. However, there was a visible slight enhancement in the gray color intensity from the left to the right coming from the circular detection volume. 


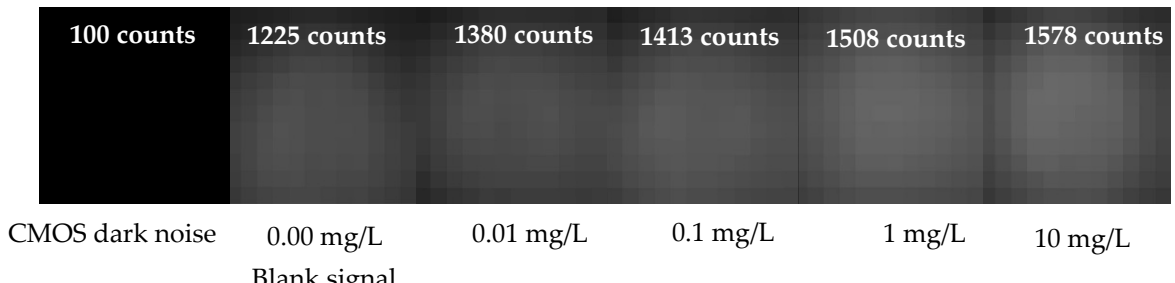

(a)

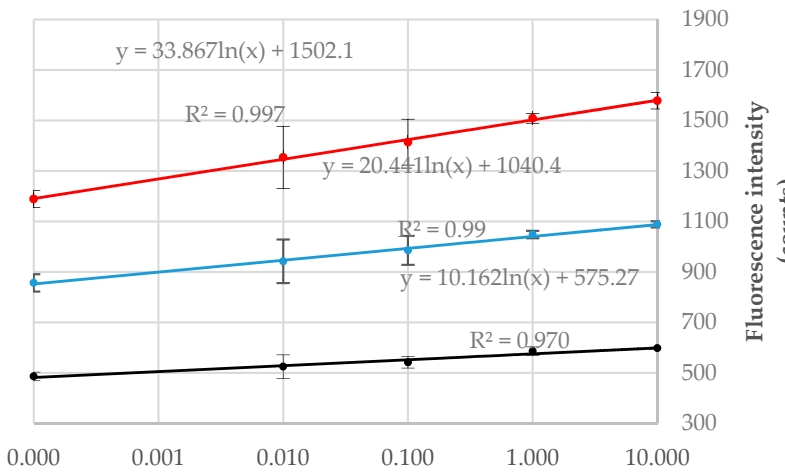

Formaldehyde concentration $(\mathrm{mg} / \mathrm{L})$

- Mean value at $\mathrm{P} 3=315 \mathrm{~mW}$ - Mean value at $\mathrm{P} 2=210 \mathrm{~mW}$

- Mean value at P1=105 mW L Log. (Mean value at P3=315 mW)

— Log. (Mean value at P2=210 mW) _L Log. (Mean value at P1=105 mW)

(b)

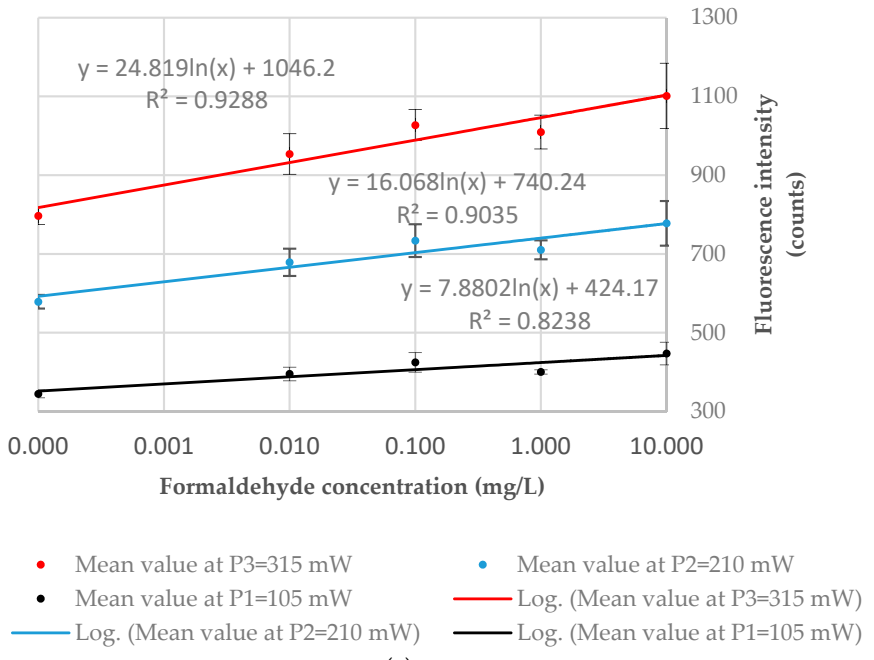

(c)

Figure 8. Experimental evaluation of the CMOS-based fluorescence detector realized using the mean values $(\bar{X})$ of seven measurements $(n=7)$ made on two independently prepared samples $(N=2)$ at each of the $c_{i}, i=0, \ldots, 4$ concentrations tested. (a) ULS 24 CMOS image sensor $12 \times 12$-pixel output for the dark current, blank signal, and the four formaldehyde concentrations tested for a quartz cell at $P=315 \mathrm{~mW}$. (b) Logarithmic fitting of the experimental points for a quartz fluidic cell. (c) Logarithmic fitting of the experimental points for a silicon fluidic cell. The error bars indicate one standard deviation $(N=2)$.

The experimental response of the CMOS-based fluorescence detector presented in Figure 8b,c shows a logarithmic correlation between the DDL fluorescence intensity and formaldehyde concentrations in DDL solutions. Analyzing the plots, it was observed that the correlation coefficients $\left(R^{2}\right)$ increased proportionally with the excitation optical power for both cells. The logarithmic behavior suggested that the concentration range tested was above the limit of linearity of the system [39]. A logarithmic 
behavior of the fluorescence signal was observed in the $0.01-10 \mathrm{mg} / \mathrm{L}$ formaldehyde concentration range for both cells, indicating that the upper limit of the linear range is most probably below the lowest concentration tested, i.e., $0.01 \mathrm{mg} / \mathrm{L}$. The RSD calculated for measurements performed on a particular sample gave values ranging from $0.06 \%$ up to $0.71 \%$ for the quartz cell (see Table 1 ) and values ranging $0.09 \%$ to $1.59 \%$ for the silicon cell (see Table 2 ). When RSDs were calculated for the duplicate samples, values ranging from $1.29 \%$ to $9.11 \%$ for the quartz cell and from $3.82 \%$ to $7.54 \%$ for the silicon cell were found. The source of errors might be related to the inherent differences that arose during the preparation of the samples, the uncontrolled temperature of the environment, and the low number of replicates. Moreover, bubbles were sometimes observed at the end of the measurement process inside the fluidic cell detection chamber. The observed fluorescence intensity mean values were higher when bubbles were present inside the chamber compared to the situation when bubbles were absent. This is why the measurements made in the presence of air bubbles occupying parts of the detection chamber were not considered when the response of the sensor was determined. The sources of error mentioned above might be the reason why the mean values obtained for the silicon fluidic cell at $c_{3}=1.0 \mathrm{mg} / \mathrm{L}$ were observed as being lower than expected for all the three optical excitation powers tested (see Figure $8 \mathrm{c}$ ). Analyzing the plot given by the other three concentrations, it could be observed that the values obtained at this concentration were below the trend line; moreover, the values obtained at $c_{3}=1.0 \mathrm{mg} / \mathrm{L}$ were lower than the values obtained at $c_{3}=0.1 \mathrm{mg} / \mathrm{L}$.

Although the results obtained were approximate, a tendency toward higher SNRs in the case of the silicon fluidic cell could be noted. The SNR obtained for the lower formaldehyde concentration tested, $c_{1}=0.01 \mathrm{mg} / \mathrm{L}$, is plotted in Figure 7a. At the maximum optical power tested, the SNR value of the quartz cell was found to be $S N R_{\text {quartz }}=4.9$, while $S N R_{\text {silicon }}=6.1$.

\section{Conclusions and Perspectives}

In conclusion, it should be noted that the main achievements registered in this work were related to the on-chip integration of the detection part of the sensor. A CMOS-based fluorescence detector was developed and proved to be capable of detecting $10 \mu \mathrm{g} / \mathrm{L}$ of formaldehyde derivatized into DDL $\left(\phi\left(20^{\circ} \mathrm{C}\right)=0.005\right)$ in a $3.5 \mu \mathrm{L}$ interrogation volume with $S N R=4.9$ and $R S D=9.1 \%(N=2)$ for a quartz fluidic cell; and with $S N R=6.1$ and $R S D=5.3 \%(N=2)$ for a silicon fluidic cell. Moreover, the enhancement of the signal intensity in the silicon fluidic cell due to its absorption coefficient at the LED emission wavelength, $a\left(\lambda_{a b s}=420 \mathrm{~nm}\right)=5 \times 10^{4} \mathrm{~cm}^{-1}$, which is approximately five times higher than the absorption coefficient at the emission wavelength, $a\left(\lambda_{e m}=515 \mathrm{~nm}\right)=9.25 \times 10^{3} \mathrm{~cm}^{-1}$, was confirmed.

Although the repeatability of the results has to be tested for more independently prepared samples in order to fully validate the system, the potential of the concept has been demonstrated through the obtained results. The logarithmic behavior of the fluorescence signal was observed in the $0.01-10 \mathrm{mg} / \mathrm{L}$ formaldehyde concentration range for both cells, indicating that the upper limit of the linear range is most probably below the lowest concentration tested, i.e., $0.01 \mathrm{mg} / \mathrm{L}$. The linear range of the system could be obtained after lowering the optical background noise level, which was observed as being relatively high.

Otherwise, the feasibility of the detection configuration has been proven, with the system showing high miniaturization and detection improvement potential. The $1 \mathrm{~mm}$ thickness band pass filter could be replaced by a filtration layer coated directly on top of the CMOS image sensor, as described by Guduru et al. [40] and Sunaga et al. [41]. This would further diminish the optical path length and lead towards a fully-integrated monolithic device. Moreover, a filterless configuration based on time-resolved detection methodology could be employed, as described by Mariuta et al. [16]. This methodology practically avoids the optical background noise, but its implementation is strictly related to the working frequency of the processor involved, since the DDL molecule fluorescence decay time is only limited to 2 ns. 
The study showed the functionality of the concept based on an orthogonal detection scheme, employing a LED-induced fluorescence technique coupled to a CMOS image sensor as an ultra-low light detection system. Due to the memory effects that were consistently observed, the fluidic channels were rinsed with acetone after each sampling.

In order to further reduce the fabrication costs, PMMA polymer, providing very good optical properties for this particular application, might be considered as the main material for the fabrication and testing of a new fluidic cell. Its implementation as a waveguide for biomedical applications and its potential for wearable and in vivo applications, which are currently being studied [42], makes it a promising material for such an application. Here, attention has to be paid to the surface roughness that results from the fabrication process, possible swelling from liquids, and its own fluorescence. Another possible direction could be represented by a full silicon structure, considering the CMOS image sensor validation for this application and the SNR enhancement observed for silicon.

In addition, the potential of this device could go beyond this specific application, contributing to the rapidly developing field of on-chip fluorescence sensing for various applications of rapid and low-cost monitoring in chemistry, biology, or environmental fields.

Regarding the challenge related to airborne $\mathrm{HCHO}$ trapping in a microfluidic context, a gas-liquid microreactor concept was proposed [16]. A disposable gas-liquid microcontactor, designed as a two-layer PMMA structure with an embedded polymeric membrane, is supposed to be integrated in between two holders equipped with an integrated heating and fluidic streaming system. Each PMMA layer of the contactor hosts a meandering network of rectangular cross-section microchannels, with one layer being assigned to the reagent streaming (liquid carrying layer) and one to the gas streaming (gas carrying layer).

After successful fabrication of the subsystems of the gas-liquid microreactor, further results are expected to experimentally prove the concept. Further analytical studies have to be performed in order to check the viability of the on-chip membrane integration technique and to study the mass transfer efficiency at different flow rates of gas and reagent streams. A mathematical model for the estimation of formaldehyde trapping in the reagent stream through a hydrophobic membrane was also developed and presented by Mariuta et al. [16]. The interest here is to enable enhanced and efficient formaldehyde trapping using cost-efficient on-chip membrane-based polymer chips. Next, a system integration study has to be performed in order to identify solutions for low-noise, cost-effective fluid pumping.

Author Contributions: Conceptualization, D.M., S.L.C., L.B., and J.J.B.; methodology D.M. and A.G.; software, D.M. and A.G.; validation, D.M., A.G., J.J.B., J.G.K., and L.B.; formal analysis, D.M. and J.J.B.; investigation, D.M.; resources, L.B., C.B., S.C., S.L.C., J.J.B., and J.G.K.; data curation, D.M.; writing-original draft preparation, D.M.; writing-review and editing, L.B., C.B.., S.C., S.L.C., J.J.B., and J.G.K.; supervision, J.J.B., L.B., J.G.K., and S.L.C.; project administration, J.J.B., L.B., S.C., C.B., and J.G.K.; funding acquisition, J.J.B. and L.B. All authors have read and agreed to the published version of the manuscript.

Funding: The work in this article has received funding from the European Union's Horizon 2020 research and innovation programme under the Marie Sklodowska-Curie grant agreement No 643095.

Acknowledgments: The authors want to acknowledge the contribution of Professor Aldo Frezzotti from Politecnico di Milano, Italy, Christian Karnutsch from Hochschule Karlsruhe, Achim Voigt, and Alexandra Moritz from Institute of Microstructure Technology, Karlsruhe. This work was partly supported by the French Renatech network under the project P-17-02324. We acknowledge support by the KIT-Publication Fund of the Karlsruhe Institute of Technology.

Conflicts of Interest: The authors declare no conflict of interest.

\section{References}

1. Household Air Pollution: Pollutants. Available online: https://www.who.int/airpollution/household/ pollutants/en/ (accessed on 24 December 2019).

2. Squire, R.A.; Cameron, L.L. An analysis of potential carcinogenic risk from formaldehyde. Regul. Toxicol. Pharmacol. 1984, 4, 107-129. [CrossRef] 
3. Casset, A.; Marchand, C.; Purohit, A.; Le Calve, S.; Uring-Lambert, B.; Donnay, C.; Meyer, P.; de Blay, F. Original article Inhaled formaldehyde exposure: Effect on bronchial response to mite allergen in sensitized asthma patients. Allergy 2006, 61, 1344-1350. [CrossRef] [PubMed]

4. Nielsen, G.D.; Larsen, S.T.; Wolkoff, P. Re-evaluation of the WHO (2010) formaldehyde indoor air quality guideline for cancer risk assessment. Arch. Toxicol. 2017, 91, 35-61. [CrossRef]

5. 5-HMF: The Key to Green Chemestry. Available online: https://5-hmf.com/ (accessed on 24 December 2019).

6. Salthammer, T.; Mentese, S.; Marutzky, R. Formaldehyde in the indoor environment. Chem. Rev. 2010, 110, 2536-2572. [CrossRef]

7. Becker, A.; Andrikopoulou, C.; Bernhardt, P.; Ocampo-Torres, R.; Trocquet, C.; Le Calvé, S. Development and Optimization of an Airborne Formaldehyde Microfluidic Analytical Device Based on Passive Uptake through a Microporous Tube. Micromachines 2019, 10, 807. [CrossRef]

8. ANSES - ANSES - French Agency for Food, Environmental and Occupational Health \& Safety. Indoor Air Quality Guidelines (IAQGs) - Formaldehyde. Available online: https://www.anses.fr/en/content/indoor-airquality-guidelines-iaqgs (accessed on 9 July 2020).

9. Guglielmino, M.; Allouch, A.; Serra, C.A.; Le Calvé, S. Development of microfluidic analytical method for on-line gaseous Formaldehyde detection. Sens. Actuators B Chem. 2017, 243, 963-970. [CrossRef]

10. Liu, J.; Li, X.; Yang, Y.; Wang, H.; Kuang, C.; Chen, M.; Hu, J.; Zeng, L.; Zhang, Y. Sensitive Detection of Ambient Formaldehyde by Incoherent Broadband Cavity Enhanced Absorption Spectroscopy Sensitive Detection of Ambient Formaldehyde by Incoherent Broadband Cavity Enhanced Absorption Spectroscopy. Anal. Chem. 2020, 92, 2697-2705. [CrossRef] [PubMed]

11. Warneke, C.; Veres, P.; Holloway, J.S.; Stutz, J.; Tsai, C.; Alvarez, S.; Rappenglueck, B.; Fehsenfeld, F.C. Airborne formaldehyde measurements using PTR-MS: Calibration, humidity dependence, inter-comparison and initial results. Atmos. Meas. Tech. 2011, 4, 2345-2358. [CrossRef]

12. Dugheri, S.; Bonari, A.; Pompilio, I.; Colpo, M.; Mucci, N.; Montalti, M.; Arcangeli, G.; Brambilla, L.G.A.; Morgagni, V.G.B. Development of an Innovative Gas Chromatography - Mass Spectrometry Method for Assessment of Formaldehyde in the Workplace Atmosphere. Acta Chromatogr. 2017, 29, 511-514. [CrossRef]

13. Cihelka, J.; Matulková, I.; Civiš, S. Laser diode photoacoustic and FTIR laser spectroscopy of formaldehyde in the $2.3 \mu \mathrm{m}$ and $3.5 \mu \mathrm{m}$ spectral range. J. Mol. Spectrosc. 2009, 256, 68-74. [CrossRef]

14. Hanoune, B.; LeBris, T.; Allou, L.; Marchand, C.; Le Calvé, S. Formaldehyde measurements in libraries: Comparison between infrared diode laser spectroscopy and a DNH-derivatization method. Atmos. Environ. 2006, 40, 5768-5775. [CrossRef]

15. Descamps, M.N.; Bordy, T.; Hue, J.; Mariano, S.; Nonglaton, G.; Schultz, E.; Tran-Thi, T.H.; Vignoud-Despond, S. Real-time detection of formaldehyde by a sensor. Sens. Actuators B Chem. 2012, 170, 104-108. [CrossRef]

16. Mariuta, D.; Baldas, L.; Colin, S.; Le Calvé, S.; Korvink, J.G.; Brandner, J.J. Prototyping a Microfluidic Sensor for Real - Time Detection of Airborne Formaldehyde. Int. J. Chem. Eng. Appl. 2020, 11, 23-28.

17. Wibisono, Y.; Cornelissen, E.R.; Kemperman, A.J.B.; van der Meer, W.G.J.; Nijmeijer, K. Two-phase flow in membrane processes: A technology with a future. J. Memb. Sci. 2014, 453, 566-602. [CrossRef]

18. Guzman, J.M.C.C.; Tayo, L.L.; Liu, C.C.; Wang, Y.N.; Fu, L.M. Rapid microfluidic paper-based platform for low concentration formaldehyde detection. Sens. Actuators B Chem. 2018, 255, 3623-3629. [CrossRef]

19. Liu, C.C.; Wang, Y.N.; Fu, L.M.; Huang, Y.H. Microfluidic paper-based chip platform for formaldehyde concentration detection. Chem. Eng. J. 2018, 332, 695-701. [CrossRef]

20. Weng, X.; Chon, C.H.; Jiang, H.; Li, D. Rapid detection of formaldehyde concentration in food on a polydimethylsiloxane (PDMS) microfluidic chip. Food Chem. 2009, 114, 1079-1082. [CrossRef]

21. Fu, L.; Wang, Y.; Liu, C. An integrated microfluidic chip for formaldehyde analysis in Chinese herbs. Chem. Eng. J. 2014, 244, 422-428. [CrossRef]

22. Pang, X.; Lewis, A.C. A microfluidic lab-on-chip derivatisation technique for the measurement of gas phase formaldehyde. Anal. Methods 2012, 4, 2013-2020. [CrossRef]

23. Zhang, X.; Sun, Y.; Fan, Y.; Liu, Z.; Zeng, Z.; Zhao, H.; Wang, X.; Xu, J. Effects of organotin halide perovskite and $\mathrm{Pt}$ nanoparticles in SnO 2 - based sensing materials on the detection of formaldehyde. J. Mater. Sci. Mater. Electron. 2019, 30, 20624-20637. [CrossRef]

24. Baldelli, A.; Jeronimo, M.; Tinney, M.; Bartlett, K. Real - time measurements of formaldehyde emissions in a gross anatomy laboratory. SN Appl. Sci. 2020, 2, 769. [CrossRef] 
25. Ryu, G.; Huang, J.; Hofmann, O.; Walshe, C.A.; Sze, J.Y.Y.; McClean, G.D.; Mosley, A.; Rattle, S.J.; Demello, J.C.; Demello, A.J.; et al. Highly sensitive fluorescence detection system for microfluidic lab-on-a-chip. Lab Chip 2011, 11, 1664-1670. [CrossRef] [PubMed]

26. Babikian, S.; Li, G.P.; Bachman, M. A Digital Signal Processing-Assisted Microfluidic PCB for On-Chip Fluorescence Detection. IEEE Trans. Components, Packag. Manuf. Technol. 2017, 7, 846-854. [CrossRef]

27. Christopoulos, T.K.; Diamandis, E. FLUORESCENCE IMMUNOASSAYS; ACADEMIC PRESS, INC.: Cambridge, MA, USA, 1996.

28. Wei, L.; Yan, W.; Ho, D. Recent advances in fluorescence lifetime analytical microsystems: Contact optics and CMOS time-resolved electronics. Sensors (Switzerland) 2017, 17, 2800. [CrossRef]

29. Galievsky, V.A.; Stasheuski, A.S.; Krylov, S.N. Improvement of LOD in Fluorescence Detection with Spectrally Nonuniform Background by Optimization of Emission Filtering. Anal. Chem. 2017, 89, 11122-11128. [CrossRef]

30. Salthammer, T. Photophysical properties of 3,5-diacetyl-1,4-dihydrolutidine in solution: Application to the analysis of formaldehyde. J. Photochem. Photobiol. A Chem. 1993, 74, 195-201. [CrossRef]

31. Pokhriyal, A.; Lu, M.; Chaudhery, V.; Huang, C.; Schulz, S.; Cunningham, B.T. Photonic crystal enhanced fluorescence using a quartz substrate to reduce limits of detection. Opt. Express 2010, 18, 24793-24808. [CrossRef]

32. Weber, M.J. Handbook of Optical Materials; CRC Press LLC: Boca Raton, FL, USA, 2003; ISBN 0849335124.

33. Măriuța, D.; Baldas, L.; Brandner, J.; Le Calvé, S.; Barrot, C.; Magaud, P.; Laurien, N. Design, optimization and manufacturing of a miniaturized fluorescence sensing device. In Proceedings of the 3rd MIGRATE International Workshop, Bastia, France, 24-29 June 2018; p. 210421.

34. Yeh, P.; Yeh, N.; Lee, C.H.; Ding, T.J. Applications of LEDs in optical sensors and chemical sensing device for detection of biochemicals, heavy metals, and environmental nutrients. Renew. Sustain. Energy Rev. 2017, 75, 461-468. [CrossRef]

35. Tanaka, K.; Choi, Y.J.; Moriwaki, Y.; Hizawa, T.; Iwata, T.; Dasai, F.; Kimura, Y.; Takahashi, K.; Sawada, K. Improvements of low-detection-limit filter-free fluorescence sensor developed by charge accumulation operation. Jpn. J. Appl. Phys. 2017, 56, 2-7. [CrossRef]

36. Choi, Y.J.; Takahashi, K.; Matsuda, M.; Hizawa, T.; Moriwaki, Y.; Dasai, F.; Kimura, Y.; Akita, I.; Iwata, T.; Ishida, M.; et al. Filter-less fluorescence sensor with high separation ability achieved by the suppression of forward-scattered light in silicon. Jpn. J. Appl. Phys. 2016, 55. [CrossRef]

37. Nakazawa, H.; Yamasaki, K.; Takahashi, K.; Ishida, M.; Sawada, K. A filter-Less multi-Wavelength fluorescence detector. In Proceedings of the 2011 16th International Conference on Solid State Sensors Actuators and Microsystems TRANSDUCERS'11, Beijing, China, 5-9 June 2011; pp. 100-103.

38. Ding, Z.; Xu, C.; Wang, Y.; Pellegrini, G. Ultra-low-light CMOS biosensor complements microfluidics to achieve portable diagnostics. Procedia Technol. 2017, 27, 39-41. [CrossRef]

39. Massart, D.L.; Auke Dijkstra, L.K. Chapter 6 Sensitivity and limit of detection. In Evaluation and Optimization of Laboratory Methods and Analytical Procedures; Elsevier: Amsterdam, The Netherlands, 1978; pp. 143-156.

40. Guduru, S.S.K.; Scotognella, F.; Chiasera, A.; Sreeramulu, V.; Criante, L.; Vishnubhatla, K.C.; Ferrari, M.; Ramponi, R.; Lanzani, G.; Vázquez, R.M. Highly integrated lab-on-a-chip for fluorescence detection. Opt. Eng. 2016, 55, 097102. [CrossRef]

41. Sunaga, Y.; Haruta, M.; Takehara, H.; Ohta, Y.; Motoyama, M.; Noda, T.; Sasagawa, K.; Tokuda, T.; Ohta, J. Implantable CMOS imaging device with absorption filters for green fluorescence imaging. In Proceedings of the Optical Techniques in Neurosurgery, Neurophotonics, and Optogenetics, San Francisco, CA, USA, 1-4 February 2014; Volume 8928, pp. 5-10.

42. Torres-Mapa, M.L.; Singh, M.; Simon, O.; Mapa, J.L.; Machida, M.; Günther, A.; Roth, B.; Heinemann, D.; Terakawa, M.; Heisterkamp, A. Fabrication of a Monolithic Lab-on-a-Chip Platform with Integrated Hydrogel Waveguides for Chemical Sensing. Sensors (Switzerland) 2019, 19, 4333. [CrossRef] [PubMed]

(C) 2020 by the authors. Licensee MDPI, Basel, Switzerland. This article is an open access article distributed under the terms and conditions of the Creative Commons Attribution (CC BY) license (http://creativecommons.org/licenses/by/4.0/). 